\title{
Práticas Intersetoriais do Programa Saúde na Escola (PSE) em Escolas Públicas da Ceilândia/DF
}

\author{
Márcia Neide de Melo Marinho Orsano \\ Graduação em Ciências Biológicas (UCB). Especialização em Saúde Pública (IBEED). Mestrado em Metodologias \\ para o Ensino de Linguagens e suas Tecnologias (Unopar). \\ $\triangle$ marciam.marinho@gmail.com \\ Andreia de Freitas Zômpero \\ Pós doutora em Ensino de Ciências. Docente da Universidade Estadual de Londrina e do Programa de Pós \\ graduação em Ensino de Ciências e Educação Matemática da Universidade Estadual de Londrina- PECEM \\ $\bowtie$ andzomp@yahoo.com.br
}

Recebido em 16 de março de 2020

Aceito em 14 de agosto de 2021

\begin{abstract}
Resumo:
Este estudo teve como objetivo analisar as formas de articulação entre os setores de saúde e educação na implementação das ações do Programa Saúde na Escola (PSE) em escolas públicas da Ceilândia/DF. O PSE se estrutura em uma política de caráter intersetorial dos ministérios da Saúde e da Educação que visa contribuir com a formação dos estudantes das escolas públicas do país, por meio de ações para promoção da saúde e de melhorias em aspectos que interferem na qualidade de vida. Esta pesquisa é de cunho qualitativo, com caráter descritivo e analítico, na qual os dados foram obtidos por meio de entrevistas semiestruturadas, realizadas no segundo semestre de 2019, com supervisores e coordenadores pedagógicos de quatro unidades escolares públicas. As análises foram realizadas de acordo com os aspectos da Análise Textual Discursiva (ATD). Após análise das entrevistas foram elencados dois eixos com respectivas categorias e subcategorias, o primeiro referente à Gestão Compartilhada e o segundo trata do Monitoramento, Avaliação e Recomendações. O estudo identificou que os recursos humanos e financeiros são aspectos limitantes das ações intersetoriais, causando prejuízos na efetividade das atividades e êxito do programa. Nesse sentido, o aporte de recursos humanos e financeiros possibilitaria melhorias no desenvolvimento das ações e facilitaria a gestão compartilhada. Verificou-se que as práticas intersetoriais apresentam fragilidades em relação à comunicação, monitoramento e avaliação das ações, necessitando de ajustes nas estratégias de implementação.
\end{abstract}

Palavras-chave: Saúde, Escola, PSE, Intersetorialidade.

\section{Intersectoral Practices of the Saúde na Escola Program (PSE) in Public Schools in Ceilândia/DF}

\begin{abstract}
:
This study aimed to analyze the articulation forms between the health and the education sectors in the implementation of the Saúde na Escola Program [Health at School Program] actions in public schools in Ceilândia/DF. The PSE is structured on an intersectoral policy of the Health and Education Ministries that aims to contribute to the students training in public schools in the country, through actions to promote health and improve elements that interfere with quality of life. This research is of a qualitative type, with descriptive and analytical nature, in which the data were obtained through semi-structured interviews, carried out in the second semester of 2019, with pedagogical supervisors and coordinators of four public school, and the analysis were carried out according to the Discursive Textual Analysis aspects. After analyzing the interviews, two axes with corresponding categories and
\end{abstract}


subcategories were listed, the first referring to Shared Management and the second dealing with Monitoring, Evaluation and Recommendations, with their categories and subcategories. The study identified that human and financial resources are limiting aspects of the program's intersectoral actions, causing losses in the effectiveness of the activities and in the success of the program. In this sense, the contribution of human and financial resources would enable improvements in the development of actions and facilitate shared management. It was found that intersectoral practices have weaknesses in relation to communication, monitoring and evaluation of actions, requiring adjustments in implementation strategies.

Keywords: Health, School, Health at School Program, Intersectoriality.

\section{Prácticas Intersectoriales del Programa Saúde na Escola (PSE) en las Escuelas Públicas de Ceilândia/DF}

\section{Resumen:}

Este estudio tuvo como objetivo analizar las formas de articulación entre los sectores de salud y educación en la implementación de las acciones del Programa Saúde na Escola (PSE) en las escuelas públicas de Ceilândia/DF. El PSE se estructura en una política intersectorial de los Ministerios de Salud y de Educación que tiene como objetivo contribuir a la formación de los estudiantes de las escuelas públicas del país, a través de acciones para promover la salud y mejoras en aspectos que interfieren con la calidad de vida. Esta investigación es de carácter cualitativo, con carácter descriptivo y analítico, en el que los datos se obtuvieron a través de entrevistas semiestructuradas, realizadas en el segundo semestre de 2019, con supervisores y coordinadores pedagógicos de cuatro unidades de escuelas públicas, y los análisis se realizaron de acuerdo con los aspectos del Análisis Discursivo Textual (DTA). Después de analizar las entrevistas, se enumeraron dos ejes con sus respectivas categorías y subcategorías, el primero referido a la Gestión Compartida y el segundo relacionado con el Monitoreo, Evaluación y Recomendaciones, con sus categorías y subcategorías. El estudio identificó que los recursos humanos y financieros son aspectos limitantes de las acciones intersectoriales del programa, causando pérdidas en la efectividad de las actividades y el éxito del programa. En este sentido, la contribución de los recursos humanos y financieros permitiría mejoras en el desarrollo de acciones y facilitaría la gestión compartida. Se encontró que las prácticas intersectoriales tienen debilidades en relación con la comunicación, el monitoreo y la evaluación de acciones, que requieren ajustes en las estrategias de implementación.

Palabras clave: Salud, Escuela, Programa de Salud Escolar, Intersectorialidad.

\section{INTRODUÇÃO}

Os programas intersetoriais governamentais, por englobarem diferentes setores, apresentam muitos desafios de implementação, planejamento e monitoramento na gestão compartilhada, uma vez que envolvem diferentes atores, sendo necessário o alinhamento de suas visões e experiências no intuito de atingir um objetivo comum.

Nessa perspectiva, o Programa Saúde na Escola (PSE) foi formulado por meio de uma ação integrada entre Ministério da Educação e da Saúde, formalizada pelo Decreto Presidencial no 6.286 de cinco de dezembro 2007, tendo como público-alvo crianças, adolescentes e adultos escolares da rede pública de ensino objetivando, por meio de suas ações, promover a saúde e a cidadania, fortalecer o enfrentamento das situações de 
vulnerabilidade social e possibilitar uma maior participação da comunidade nas políticas públicas das áreas de saúde e educação (BRASIL, 2007).

O PSE busca, por meio da intersetorialidade, um novo olhar sobre a forma de se pensar e implementar políticas públicas em setores diversos com ações compartilhadas. Segundo Junqueira (1998, p. 12) "O conceito de intersetorialidade surge como uma possibilidade de solução integrada dos problemas do cidadão, considerando-o na sua totalidade".

Nesse sentido, a integração dos setores saúde e educação, proposta pelo PSE, torna-se um diferencial na busca de estratégias para atender as demandas sociais e garantir os direitos fundamentais superando o modelo de gestão pública fragmentada e centralizada.

Ao longo do tempo, a relação entre saúde e educação sofreu transformações no espaço escolar. Anteriormente a saúde direcionava suas ações em medidas preventivas e higienista de controle de patologias, que apresentaram resultados insatisfatórios na promoção da saúde. Atualmente, a promoção da saúde do estudante é compreendida de forma integral e considera como elementos para promoção da saúde as situações habitacionais, a qualidade ambiental, a educação, a distribuição de renda, o acesso aos serviços públicos, a alimentação e, principalmente, em relação à igualdade de direitos, em que o foco é fomentar os hábitos de vida saudáveis para melhorar a qualidade de vida da população (ORGANIZAÇÃo PANAMERICANA DA SAÚDE, 2006).

Nesse contexto, a escola destaca-se como local fecundo e estratégico para promoção da saúde, por nela existir um grande fluxo de saberes e experiências representado pelos estudantes, professores, familiares dos estudantes e comunidade que apresentam a matéria prima para traçar os caminhos de compreensão das demandas sociais, planejamento e execução das ações de projetos e programas governamentais que integram saúde e educação (ORGANIZAÇÃO PAN-AMERICANA DA SAÚDE, 2006).

Neste estudo buscou-se responder como as escolas que aderiram ao programa PSE estão trabalhando as ações intersetoriais e quais fatores interferem na implementação dessas ações. Esta pesquisa justifica-se ao procurar identificar as estratégias locais de organização, planejamento e ações intersetoriais do âmbito escolar relacionadas ao PSE, possibilitando uma melhor compreensão das dificuldades e acertos da implementação do programa em unidades escolares localizadas em uma região de grande vulnerabilidade social como, por 
exemplo, condições inadequadas de moradia, ausência de saneamento básico em algumas localidades e dificuldades de acesso aos serviços de atenção básica à saúde, entre outras. Dessa forma, a pesquisa vem com o intuito de contribuir com recomendações que poderão minimizar as lacunas da atenção básica à saúde no que se refere ao acompanhamento da saúde da população inserida na escola exposta às vulnerabilidades sociais.

Nesse contexto, este estudo tem por objetivo analisar as formas de articulação entre os setores de saúde e educação na implementação das ações do Programa Saúde na Escola (PSE) em escolas públicas da Ceilândia/DF.

\section{A promoção da saúde na Escola}

Na Carta de Ottawa, em 1986, primeira conferência internacional sobre o tema, os países participantes assumiram que as ações de promoção da saúde deveriam resultar na diminuição das iniquidades em saúde, de forma a garantir a todos os cidadãos a oportunidade de fazerem escolhas mais favoráveis e serem os atores principais no processo de produção da saúde e melhoria da qualidade de suas vidas (BUSS E CARVALHO, 2009). Essa carta define promoção da saúde como "processo de capacitação da comunidade para atuar na melhoria da sua qualidade de vida e saúde, incluindo maior participação no controle desse processo" (BRASIL, 2002, p. 19).

Nessa perspectiva, a Política Nacional de Promoção da Saúde (PNPS) foi aprovada pela Portaria nº 687 de 30 de março de 2006, considerando-se os reflexos dos indicadores sociais na temática saúde e fundamentada na visão da intersetorialidade com o intuito de atender às demandas sociais e propiciar melhores condições de vida a população (BRASIL, 2006)

A intersetorialidade, assim, fundamenta-se em uma prática integradora de ações de distintos setores que se articulam, complementam e interagem para uma aproximação mais intrincada dos problemas e seu enfrentamento, compartilhando recursos e metas e desenvolvendo estratégias em conjunto (WIMMER E FIGUEIREDO, 2006).

No âmbito da saúde, a intersetorialidade ocorre, por exemplo, de maneira que as equipes de atenção primária à saúde trabalhem mediante a interlocução escola/equipe no desenvolvimento de ações dentro de seu território de abrangência, visando fortalecer a oferta 
das políticas sociais como forma de propiciar o acesso da população à saúde, o que remete à concepção de um conceito abrangente de saúde (DONDONI, 2016).

Nesse contexto, considera-se que a escola é um local privilegiado de encontro da educação e da saúde, um espaço para a convivência social e para o estabelecimento de relações favoráveis à promoção da saúde pelo viés de uma educação integral. Desse modo, o Programa Saúde na Escola (PSE) se coloca em local de destaque, pois fortalece as ações das políticas públicas de saúde e educação voltadas às crianças, adolescentes, jovens e adultos, funcionando de forma compartilhada e envolvendo vários atores sociais e governamentais em todas esferas, municipais, estaduais e federais (FIGUEIREDO, MACHADO e ABREU, 2010).

\section{PERCURSO METODOLÓGICO}

O presente estudo possui vinculação com as perspectivas da pesquisa qualitativa com caráter descritivo e analítico, segundo Lüdke e André (2013), a pesquisa qualitativa considera o ambiente natural como fonte direta dos dados, que são predominantemente descritivos, ou seja, preocupação com o processo é muito maior que o produto, os significados que as pessoas dão as coisas e a sua vida são focos de atenção.

Esta pesquisa foi realizada em quatro unidades de ensino, situadas em Ceilândia região administrativa do Distrito Federal. Fizeram parte da pesquisa 11 participantes, coordenadores e supervisores pedagógicos das escolas públicas selecionadas.

Os dados foram obtidos por meio de entrevistas semiestruturadas. De acordo com Richardson (2014), a entrevista como procedimento de pesquisa possibilita uma interação entre o pesquisador e os participantes da pesquisa. Nesse sentido, a conversa e troca de experiências apresentam um cenário fecundo de possibilidades para construção do conhecimento do objeto do estudo ou fenômeno a ser compreendido.

As entrevistas seguiram um cronograma aprovado previamente pela pesquisadora e participantes, tendo sido realizadas no mês de setembro de 2019 nas unidades de ensino. Para realização das entrevistas foi elaborado um roteiro cujas perguntas, validadas por pesquisadores de um grupo de pesquisa, apresentavam elementos para atender os objetivos 
deste estudo. Todas as entrevistas foram gravadas para exploração e análise do conteúdo na íntegra. Em seguida, as entrevistas foram transcritas, analisadas e registradas nos diários da pesquisadora. Esse material resultou na produção de um documento que foi posteriormente assinado pelos entrevistados (coordenadores e supervisores), para legitimar o processo de concordância da cessão de informações.

A interpretação dos dados coletados nas entrevistas deu-se por meio da Análise Textual Discursiva (ATD). Para Moraes (2003) a ATD, aplicada em pesquisas de caráter qualitativo, busca a compreensão dos fenômenos pesquisados e se organiza em quatro focos, compostos por um ciclo de três elementos, a saber: 1) Desmontagem dos textos - que permite a análise nas minúcias das informações coletadas; 2) Estabelecimento de relações - em que se associa as informações com ideias convergentes por meio de categorias; 3) Captação do novo emergente - representa a visão do pesquisador resultante das análises dos elementos do fenômeno investigado. Por fim, o quarto foco que é um processo auto-organizado que se expressa em novas compreensões do fenômeno estudado a partir dos três elementos.

As perguntas foram organizadas em dois eixos, o primeiro se refere à gestão compartilhada e o segundo apresenta elementos de avaliação, registro e recomendações do programa, conforme Quadro 1.

Quadro 1 - Eixos para Organização da Entrevista

\section{EIXO I - Gestão Compartilhada}

1) Como ocorre o planejamento e execução das ações que serão realizadas entre a escola e agentes da saúde?

2)Já ocorreram alterações de gestores da escola ou da unidade de saúde que geraram descontinuidade ou atraso nas ações previstas do programa? Comente.

3) Quais aspectos negativos e positivos de implementar ações na escola com a participação do setor de saúde?

4) Existem recursos humanos adequados para execução das ações do programa? A escola deixou de selecionar e executar alguma ação devido à insuficiência de recursos?

\section{EIXO II - Avaliação, Registro e Recomendações}

5) No final do ano letivo é produzido um relatório das ações executadas do programa? Se sim, esses relatórios são disponibilizados em quais meios?

6) Como o programa é avaliado? De que maneira os resultados são disponibilizados para comunidade?

7) Quais as recomendações para melhorias na gestão do programa na escola?

Fonte: A autora.

Os princípios éticos nortearam esta pesquisa - aprovada pelo Comitê de Ética em Pesquisa, oficializada por meio do parecer 3.508.963 em agosto de 2019. Cada entrevista foi precedida da leitura e explicação detalhada do Termo de Consentimento Livre e Esclarecido 
(TCLE), sendo as perguntas iniciadas somente após a concordância expressa do/a participante.

\section{RESULTADOS E DISCUSSÃo}

Nesta pesquisa, o processo de organização e análise dos dados fundamentaram-se na Análise Textual Discursiva (ATD) estruturada por Moraes e Galiazzi (2007), na primeira fase, por três elementos: unitarização, categorização e captação do novo emergente e a segunda fase com a comunicação de uma nova compreensão do fenômeno estudado, que resulta no metatexto, encerrando o ciclo da ATD.

No primeiro passo, nomeado de "desmontagem textual" os documentos do corpus coletados foram lidos em um processo de análise dinâmico de ordem e desordem, não linear e instável de múltiplas significações e ressignificações. Da desconstrução textual surgiram os dois eixos, que foram desenhados em função dos objetivos da pesquisa. No segundo passo, chamado de categorização, fez-se o agrupamento a partir da análise das respostas dos entrevistados e das relações percebidas, momento em que comparava-se os elementos e buscava-se seus sentidos. No terceiro passo, chamado de captação do novo emergente, ocorreu a construção do metatexto a partir da interpretação, compreensão dos sentidos e significados. Por fim, na segunda fase, nomeada de comunicação em que apresenta-se novas compreensões e significados em relação ao objeto da pesquisa.

Conforme mencionado anteriormente, estabeleceu-se dois eixos tomando-se por base o roteiro das entrevistas. 0 primeiro trata da gestão compartilhada entre os agentes de saúde e os gestores educacionais e o segundo apresenta elemento de avaliação, registro e recomendações do programa. A partir da análise das respostas dos entrevistados foram organizadas as categorias emergentes e suas subcategorias, de acordo com as convergências dos relatos.

Os profissionais entrevistados foram identificados em seus depoimentos por meio de letras P de participante e pela ordem numérica das entrevistas (P1, P2, P3, P4...), como forma de garantir o anonimato dos entrevistados. As falas serão apresentadas fazendo parte do 
texto, entre aspas, seguida da indicação do participante que a pontuou. Destaca-se ainda, que alguns trechos dos relatos dos entrevistados, que sustentam os argumentos de formação das subcategorias foram grifados com intuito de facilitar a compreensão do leitor.

A seguir no quadro II apresenta-se o eixo I que elenca repostas relativas à gestão compartilhada. Nesse eixo foram elencadas três categorias e seis subcategorias.

Quadro 2 - Eixo I- Gestão Compartilhada.

\begin{tabular}{|l|l|}
\hline \multicolumn{2}{|c|}{ GESTÃo COMPARTILHADA } \\
\hline \multirow{2}{*}{ CATEGORIA 1 - Planejamento das Ações } & Subcategoria 1.1 - Reuniões Intersetoriais \\
\cline { 2 - 3 } & Subcategoria 1.2 - Ausência de Planejamento \\
\hline $\begin{array}{l}\text { CATEGORIA 2 - Avaliação da Gestão } \\
\text { Compartilhada }\end{array}$ & Subcategoria 2.1 - Aspectos positivos \\
\cline { 2 - 3 } & Subcategoria 2.2 - Aspectos negativos \\
\hline $\begin{array}{l}\text { CATEGORIA 3 - Adequação dos recursos } \\
\text { humanos e Financeiros }\end{array}$ & Subcategoria 3.1 - Recursos Inadequados \\
\cline { 2 - 3 } & Subcategoria 3.2 - Recursos Adequados \\
\hline
\end{tabular}

Fonte: A autora.

\section{Categoria 1: Planejamento das Ações}

A Categoria 1 reúne respostas dos entrevistados que mencionaram como as ações são planejadas pelos gestores educacionais e os agentes de saúde. A partir da análise das respostas elabora-se as duas subcategorias.

A Subcategoria 1.1 (Reuniões intersetoriais) representa as escolas que realizam o planejamento das ações do PSE por meio de reuniões com gestores educacionais e da saúde, a Subcategoria 1.2 contempla os gestores que não apresentaram as formas de planejamento e articulações das ações entre a saúde e a educação.

A subcategoria mais recorrente que contemplou nove das respostas dos onze coordenadores e supervisores participantes foi a Subcategoria 1.1, que contém a reunião intersetorial como prática de planejamento das ações do programa, conforme alguns relatos a seguir:

[...] A coordenadora do PSE sai da escola e aí tem reuniões, a primeira reunião que foi feita junto com o pessoal da regional que tem um coordenador lá da UNIEB que articula isso, aí depois disso eu fui diretamente no posto e a gente organizou quais as ações seriam feitas [...] (P1). 
[...] A coordenadora do PSE da escola participa de reuniões na regional de ensino e ocorre uma adequação das ações ao calendário da realidade escolar [...] (P5).

Como pode-se verificar nos relatos dos coordenadores e supervisores o planejamento das ações ocorre a partir de reuniões com representantes das escolas e das unidades básicas de saúde, em que se considera o cronograma escolar e especificidades de cada escola e a disponibilidade dos agentes de saúde.

De acordo com Junqueira (2004), na intersetorialidade o planejamento é um instrumento relevante que possibilita o monitoramento e avaliação dos resultados, bem como a reflexão no processo de implementação para ajustes de estratégias e metas, quando necessário. Nesse sentido, a tomada de decisões compartilhadas por meio das reuniões com representantes das áreas da educação e saúde são momentos relevantes de trocas de saberes, experiências e de diálogo para o sucesso do trabalho em rede proposto pelo PSE.

A Subcategoria 1.2 representa os gestores que não mencionaram as formas de planejamento das ações do PSE. Conforme foi identificado na fala dos supervisores P8 e P11, a seguir:

[...] Não participei de nenhuma ação esse ano e não tenho informação de como era articulado". [...] (P8).

"[...] É um trabalho feito pelo SOE (Serviço de Orientação Educacional) e nós estávamos sem o serviço de orientação educacional, então quem fazia esse trabalho era a direção da escola [...]" (P11).

Compreende-se que as lacunas de comunicação, seja ela intra ou interinstitucional, podem acarretar prejuízos a implementação e sucesso do PSE, pois os gestores educacionais são peças chaves na efetividade das ações e articuladores importantes da comunidade escolar. Pode-se considerar que é por meio deles que as informações chegam aos estudantes, pais, professores e comunidade. Além disso, a sensibilização e envolvimento do público-alvo depende de intervenções desses gestores. Nesse sentido, Garajau (2013a) afirma que o senso de responsabilidade é um dos princípios da intersetorialidade. Segundo a autora a ação intersetorial necessita de esforços entre as áreas envolvidas para resolução de questões sociais. 


\section{Categoria 2: Avaliação da Gestão Compartilhada}

A categoria 2 reúne as respostas dos coordenadores e supervisores que mencionaram fatores positivos e negativos do trabalho compartilhado com os representantes da saúde, em seguida organizou-se duas subcategorias baseadas na análise das respostas dos participantes. A Subcategoria 2.1 apresenta os aspectos positivos do trabalho integrado e a Subcategoria 2.2 os aspectos negativos do trabalho integrado.

$\mathrm{Na}$ Subcategoria 2.1 estão inseridas as respostas que apresentam os aspectos positivos do trabalho compartilhado entre educação e saúde, verificado nos relatos a seguir:

[...] Só vejo ponto positivo, porque a escola ganha muito com isso, conseguindo várias ações, quando temos que encaminhar os alunos para o posto de saúde ficou mais fácil $[\ldots .].(\mathrm{P} 1)$.

[...] O aspecto positivo é o contato rápido e preventivo e contato direto com os profissionais de saúde na escola [...] (P10).

Dos onze entrevistados nove destacaram pontos positivos na realização de ações compartilhadas com a área da saúde. Os participantes apontam que a presença dos agentes de saúde na escola facilita o acesso dos estudantes aos serviços básicos de atenção à saúde, promove a conscientização da comunidade escolar e possibilita ao setor da saúde o contato direto com os problemas que acometem os estudantes.

Admite-se que as ações compartilhadas entre educação e saúde na escola contribui para resolução de problemas que necessitam de esforços dos dois setores. A interação que se estabelece de troca de conhecimentos e experiências possibilita a vivência mais realista dos conflitos que acometem os estudantes, de modo a facilitar os acessos deles aos serviços básicos de saúde, bem como promover mudanças de hábitos, assim, consequentemente traz melhorias para a qualidade de vida.

Nesse sentido, a intersetorialidade é uma ruptura na forma de fazer políticas públicas que considera os problemas sociais de maneira compartimentada, cujas demandas dos indivíduos não são entendidas na sua integralidade, pois a união de setores diferentes para o desenvolvimento de programas ou projetos possibilita maior eficiência na busca de caminhos para resolver os problemas sociais (JUNQUEIRA, INOJOSA e KOMATSU, 1997). 
A Subcategoria 2.2 apresenta os aspectos negativos do trabalho compartilhado entre educação e saúde, conforme alguns relatos a seguir:

[...] Na UBS, a gerente saiu, agora vai ter que fazer uma nova reunião para colocar ela a par do projeto tudo de novo, aí o coordenador da regional disse que vai providenciar essa reunião. Entendeu? Para fazer essa apresentação, esse elo de ligação, tudo isso gerou um atraso nas ações [...] (P1).

[...] Já o aspecto negativo é a falta da continuidade efetiva do programa [...] (P10).

Os participantes relataram como ponto negativo as mudanças de gestores da área da saúde que acarretaram atrasos e dificuldades para implementação de algumas ações. 0 participante P8 apontou como aspecto negativo a saída do supervisor da escola que resultou na perda do histórico do programa.

A falta de recursos financeiros foi destacada pelos participantes P2, P3, P4 e P5, segundo os gestores a insuficiência de recursos limita e dificulta a implementação de ações e impossibilita que os alunos realizem atividades fora da escola.

Em relação aos recursos humanos os participantes P4, P7, P8, P9 e P11 apresentam como negativo o número de profissionais da saúde, pois a demanda é grande e o número de agentes inadequado, além disso, citam a necessidade da participação da especialidade psicologia, entre os profissionais da saúde que atuam nas escolas para tratarem os casos de depressão e automutilação, que vêm crescendo nas unidades escolares nos últimos anos.

Nessa perspectiva, Santos (2011) afirma que a intersetorialidade na política pública deve ter como princípio o atendimento das demandas da população por meio da disponibilização dos serviços públicos e garantia dos direitos sociais.

\section{Categoria 3: Adequação dos Recursos Humanos e Financeiros}

Para elaboração da categoria 3 pergunta-se aos entrevistados se os recursos humanos e financeiros são adequados para execução das ações do programa. A partir da análise das respostas agrupa-se em duas subcategorias. A Subcategoria 3.1 (Recursos inadequados) representa os participantes que afirmam que os recursos são insuficientes para execução das ações, a Subcategoria 3.2 (Recursos Adequados) contempla os participantes que consideram que os recursos disponibilizados são adequados para implementação das ações do programa. 
A Subcategoria 3.1 representa os participantes que consideram os recursos inadequados, conforme alguns relatos a seguir:

[...] Na verdade já tentamos de certa forma enxugar ideias que nós temos, projetos temos, mas a questão de determinados projetos nós não conseguimos ir tão além quanto pensamos por falta desses recursos [...] (P4).

[...] A meu ver foram poucas ações executadas, mas as que foram propostas foram executadas e talvez possa ser por conta de recursos. Acredito que foram poucas e poderiam ser mais variadas [...] (P10).

De acordo com os participantes P2, P4, P5, P9, P10 e P11 os recursos financeiros são inadequados, tendo como consequência a redução das ações, e dificuldade de participação dos estudantes em atividades em outros ambientes, ou seja, fora da escola.

A Subcategoria 3.2 contempla os participantes que consideraram os recursos adequados, de acordo com alguns relatos a seguir:

[...] Todas as ações que nós selecionamos só quem ficou à frente foi a gente da escola e a gerente do posto de saúde, a gente não teve nada da secretaria de educação de recursos, nenhum recurso extra [...] (P1).

[...] Eu acho que diante do que já foi oferecido, principalmente recursos humanos foi bem satisfatório. Financeiramente a gente não tem nenhum auxílio, então quando tem que desenvolver alguma atividade pedagógica, a gente costuma usar o material da própria escola [...] (P3).

Segundo os relatos dos participantes P1, P3, P5 e P6, mesmo não ocorrendo aporte de recursos para o programa, por parte dos Ministérios da saúde e da educação, as ações foram implementadas com recursos da própria escola e conseguiram desenvolver um bom trabalho.

A partir dos relatos, observa-se que existe uma insatisfação dos gestores na questão financeira destinada ao programa, mesmo os que mencionaram que os recursos são adequados, destacaram que se a escola recebesse recursos adicionais as ações seriam mais diversifificadas e teriam maior efetividade e frequência. 
A seguir no quadro III apresenta-se o eixo II que elenca repostas relativas ao monitoramento, registro e avaliação das ações do PSE. Nesse eixo foram elencadas três categorias e sete subcategorias.

Quadro 3 - Eixo II - Monitoramento, Avaliação e Recomendações

\begin{tabular}{|l|l|}
\hline \multicolumn{2}{|l|}{ MONITORAMENTO, AVALIAÇÃo e RECOMENDAÇÕES } \\
\hline \multirow{3}{*}{$\begin{array}{l}\text { CATEGORIA 1 - Monitoramento } \\
\text { e Comunicação }\end{array}$} & Subcategoria 1.1 - Relatório GoogleDrive \\
\cline { 2 - 2 } CATEGORIA 2 - Avaliação do PSE & Subcategoria 1.2 - Não souberam responder \\
\hline \multirow{3}{*}{ CATEGORIA 3 -Recomendações } & $\begin{array}{l}\text { Subcategoria 2.1 - Avaliação da Regional de Ensino } \\
\text { financeiros }\end{array}$ \\
\cline { 2 - 2 } & Subcategoria 3.2 - Continuidade das ações \\
\cline { 2 - 2 } & Subcategoria 3.3 - Divulgação/Comunicação \\
\hline
\end{tabular}

Fonte: A autora

\section{Categoria 1: Monitoramento e Comunicação}

A categoria 1 apresenta o agrupamento das respostas dos entrevistados que apontaram a forma de registro das ações executadas e os meios de disponibilização. Com a análise da convergência dos relatos organiza-se duas subcategorias. A Subcategoria 1.1 apresenta os gestores que utilizam o GoogleDrive para registrar os relatórios e a Subcategoria 1.2 os gestores que não souberam responder as formas que as ações são registradas

A Subcategoria 1.1 reúne respostas dos gestores que utilizam o GoogleDrive por meio do formulário da secretaria de educação para registrar os relatórios, conforme alguns relatos a seguir:

[...] É feito através de um formulário que é preenchido no GoogleDrive, ele é compartilhado e a regional tem acesso [...] (P3).

[...] Sim, nós tínhamos que enviar um relatório periodicamente das atividades realizadas e durante nas reuniões a gente colocava os resultados, comparando com os anos anteriores e com outras escolas, de acordo com que cada uma ia realizando e tendo sucesso ou não, naquilo que fazia. Em relação aos relatórios eles não são disponibilizados no site da secretaria de educação. Os relatórios eram feitos de forma 
conjunta, secretaria da educação e da saúde, sempre respondíamos o formulário em juntos (P7).

De acordo com os participantes P1, P2, P3, P4, P5 e P7 os resultados das ações são registrados por meio de relatórios inseridos em um formulário da regional de ensino, via plataforma GoogleDrive. Em relação os canais de comunicação, em que os relatórios são disponibilizados, os participantes P1, P3 e P5 apontam que ficam na regional de ensino. Já P2 relata que a divulgação fica por conta dos gestores da saúde e P7 menciona que não são disponibilizados no site da secretaria. Além disso, os participantes P1 e P4 afirmam que não têm acesso aos relatórios produzidos pelos agentes da saúde.

A Subcategoria 1.2 contempla os participantes que não souberam responder as formas que os resultados das ações do programa são registrados e disponibilizados, de acordo com alguns relatos a seguir:

[...] Essa questão é uma questão interna que a escola desenvolve, isso eu não tenho muito conhecimento, não é uma coisa muito pública (P6).

[...] Não tenho conhecimento se eram produzidos e disponibilizados em alguma fonte (P8).

Os participantes P6, P8, P9, P10 e P11 apontam que desconhecem ou não tem muito conhecimento sobre a produção de relatórios do programa e os mecanismos de disponibilização desses.

Compreende-se que os programas governamentais de longo prazo, como o caso do PSE, devem possuir uma plataforma de armazenamento de informações, com resultados parciais das ações que possibilite o monitoramento das atividades por parte de qualquer cidadão.

A partir dos relatos, percebe-se que existem dificuldades de acesso aos relatórios que são produzidos pela saúde e na divulgação de como são produzidos por parte dos gestores educacionais da forma de monitoramento das ações. Nesse sentido, Garajau (2013b) afirma que a execução do trabalho intersetorial exige um empenho coletivo das áreas envolvidas para atingir os objetivos comuns que é o enfrentamento dos problemas sociais. 


\section{Categoria 2: Avaliação do PSE}

A categoria 2 contempla as respostas dos participantes que mencionaram sobre a avaliação do programa e os meios de disponibilização dos resultados para comunidade, desta forma, a partir da análise das respostas elabora-se duas subcategorias. A Subcategoria 2.1 apresenta os participantes que relatam que a avaliação do programa é realizada pela regional de ensino e a Subcategoria 2.2 os participantes que não souberam responder se existe ou não avaliação.

Na Subcategoria 2.1 os participantes relatam que a avaliação do programa é realizada pela regional de ensino, conforme pode-se verificar em alguns relatos a seguir:

[...] Não, não foi feita nenhuma avaliação externa, o que nós fazemos é da secretaria de educação que manda para gente, o coordenador da regional (P1).

[...] Eu creio que sim através da regional de ensino, de acordo com os relatórios que nós entregávamos, eles devem fazer algo nesse sentido, mas na escola não tivemos nenhum avaliador externo e não tivemos acesso a avaliação da secretaria de educação (P7).

Os participantes P1, P2 e P7 afirmam que a avaliação do programa ocorreu por meio da regional de ensino, além disso, P1 e P7 ressaltaram que não foi realizada nenhuma avaliação externa por avaliadores representantes de outros órgãos.

A subcategoria que contemplou seis, das respostas dos onze coordenadores e supervisores, foi a Subcategoria 2.2 que os participantes P4, P5, P6, P9, P10 e P11 mencionam não ter conhecimento se o programa é avaliado, conforme descrito em alguns relatos a seguir:

[...] Avaliadores externos que eu tenha conhecimento, não. Não tenho essa informação (P4).

[...] Não, nunca vi nenhum avaliador externo aqui, nunca ouvi falar, acredito que isso não aconteceu ainda (P6).

De acordo com os relatos de P4, P5, P6, P9, P10 e P11 as informações referentes ao processo de avaliação não tinham chegado até eles. Os participantes P3 e P8 não foram inseridos em nenhuma subcategoria, pois P3 relata que a avaliação é realizada na própria 
escola e que avaliação externa não ocorreu, enquanto P8 aponta que ocorre somente as visitas dos agentes da saúde, conforme relatos a seguir:

[...] A gente faz semestralmente uma avaliação de todos os projetos da escola. Avaliação externa do programa nunca ocorreu (P3).

[...] Só a visita do pessoal do posto de saúde, avaliadores não (P8).

A partir dos relatos dos entrevistados, constata-se, pois, que nenhuma das quatro escolas pesquisadas tiveram avaliação de consultores externos do programa, isto é, o Ministério da educação e saúde, além disso, seis gestores dos onze entrevistados não sabiam se a avaliação tinha sido realizada ou não. Dessa forma, entende-se que existem fragilidades de comunicação no processo de avaliação do programa.

\section{Categoria 3: Recomendações}

A categoria 3 reúne as respostas dos entrevistados que apontaram recomendações para melhorias na gestão, a partir da análise das respostas agrupa-se três subcategorias. A Subcategoria 3.1 apresenta os participantes que mencionaram o aporte de recursos humanos e financeiros, a Subcategoria 3.2 os participantes que apontam a continuidade das ações e a Subcategoria 3.3. que contempla os participantes que relatam a divulgação/comunicação do programa e seus resultados.

A subcategoria mais recorrente que contemplou sete das respostas dos onze coordenadores e supervisores foi a Subcategoria 3.1, na qual os participantes P1, P2, P3, P5, P6, P7 e P11 recomendam o aporte de recursos humanos e financeiros, conforme descrito em alguns relatos a seguir:

[...] Recursos financeiros para subsidiar outras atividades que são diferentes das que são oferecidas e talvez uma quantidade maior de atividades (P3).

[...] Eu recomendaria a questão de recursos émuito importante que isso seja discutido e traga mais recursos [...] (P6). 
Os participantes P1, P2, P3, P5, P6, P7 e P11 destacaram que o incremento de recursos financeiros possibilitaria a inclusão de mais atividades, a realização de ações em outros lócus e o melhor desenvolvimento do programa. Em relação aos recursos humanos, P5 e P11 mencionaram a necessidade da presença de um atendimento psicológico para os estudantes. Já o participante P7 recomenda o aumento do número de profissionais da saúde.

Entende-se que os recursos financeiros das escolas públicas são insuficientes para atender as demandas de um programa desse porte, se considerado que faltam recursos para manutenção básica das escolas, como reparos da estrutura elétrica, hidráulica, piso, entre outros. Além disso, o número de agentes de saúde em exercício é insatisfatório em todo o país, o que limita a efetividade desses nas atividades nas escolas.

A subcategoria 3.2 apresenta os participantes P3, P8, P9 e P10, que relataram como recomendação a continuidade das ações do programa, conforme descrito em alguns relatos a seguir:

o que eu as vezes acho é que existe um espaçamento muito grande entre uma atividade e outra, muito pontual, que fosse mais rotineiro, um intervalo menor. Os agentes de saúde são muito solícitos sempre que temos contato com eles (P3).

Que seja anual com apoio do serviço de saúde, anual mesmo, que não seja esporádico, que seja um programa que se inicia e vá até o final do ano nessa comunidade escolar (P8).

Os participantes P3, P8, P9 e P10 recomendam que as ações do programa sejam mais frequentes e que se tornem rotineiras nas escolas, haja vista o intervalo que existe entre uma ação e outra, caso que compromete a efetividade das ações.

Compreende-se que um programa de longo prazo, como o PSE, necessita de um compromisso governamental, em todas as esferas, de manter o cronograma de ações e fomentar a implementação dessas para atingir às metas propostas.

$\mathrm{Na}$ Subcategoria 3.3 os participantes recomendam melhorias na divulgação/comunicação do programa, conforme pode-se verificar a seguir:

[...] a questão de a publicidade a comunidade escolar ter mais conhecimento sobre isso. Acho que as pessoas tomarem o conhecimento disso é muito importante. Com 
certeza, há muitos professores da escola que não sabem nem o que significa o PSE, então, a publicidade dentro da própria escola deveria ser melhorada (P6).

[...] Que seja apresentado os resultados para a comunidade escolar, eu acho que a comunidade não tem esses resultados do PSE e que seja mais sistemático, mais visível, acho que pode ter sido apresentado, mas não para a comunidade escolar que foi atendida [...] (P8).

Os participantes P6 e P8 mencionam que existem falhas na divulgação do programa, tanto para a comunidade quanto para os próprios professores, dessa forma, recomendam melhorias nas formas de divulgação dentro e fora da escola.

A participante P4 não foi inserida em nenhuma das categorias, pois é o único entrevistado que recomenda a criação de polos de atendimento, de acordo com o relato a seguir:

[...] É bom setorizar as ações, só que também muito setorizadas, a gente acaba se perdendo, então, a criação de polos são importantes. Se tivéssemos polos de atendimentos razoável, se fosse aqui por exemplo que eu me encontro na Expansão do Setor O, da área do P Norte, P Sul, tendo em vista, que a área da Ceilândia/DF ser muito grande. [...] (P4).

De acordo com a participante P4, a cidade satélite de Ceilândia/DF é muito grande, e a criação de polos nos bairros possibilitaria um atendimento mais efetivo. A partir dos relatos dos entrevistados, compreende-se que a divulgação do programa apresenta lacunas em relação a comunidade escolar, dentro e fora da escola, e entre os gestores da saúde e educação. Tais situações podem comprometer o sucesso do trabalho integrado e consequentemente interferir na consolidação das políticas públicas intersetoriais.

\section{CONSIDERAÇÕES FINAIS}

O PSE, como um Programa Intersetorial, une as áreas de saúde e educação em uma nova proposta de fazer políticas públicas, em que se compreende que os caminhos de enfrentamento dos problemas sociais exigem uma visão integrada das demandas sociais e consequentemente carecem de estratégias de ações coletivas dos setores governamentais, que compartilham seus conhecimentos e experiências na busca de efetividade no atendimento. 
Os resultados obtidos, neste estudo, indicam que a intersetorialidade, apesar de encontrar barreiras para ser desenvolvida, possibilitou benefícios para os estudantes e comunidade, por meio das ações do trabalho de equipe integrado que compartilhavam do objetivo comum de promoção da saúde e estímulo a mudança de hábitos desse público-alvo.

Em relação à cooperação entre os representantes dos dois setores, saúde e educação, observa-se que a comunicação entre eles precisa ser mais efetiva e o processo de avaliação dos resultados deve ter mais publicidade, ou seja, as informações ficarem disponíveis nas escolas, no site da secretaria de educação e da saúde, para que todos os atores envolvidos tenham acesso.

Evidenciou-se que os recursos humanos e financeiros são aspectos limitantes das ações intersetoriais do programa, causando prejuízos na efetividade das atividades e êxito do programa. Nesse sentido, o aporte de recursos humanos e financeiros possibilitaria melhorias no desenvolvimento das ações e facilitaria a gestão compartilhada.

Identificou-se que a presença dos agentes de saúde na escola facilita o acesso dos estudantes aos serviços básicos de atenção à saúde, promove a conscientização da comunidade escolar e possibilita ao setor da saúde o contato direto com os problemas que acometem os estudantes.

Por fim, espera-se que esta pesquisa possa contribuir para reflexões da prática intersetorial na escola e relevância do programa nas melhorias das condições de vida da população, reforçando a compreensão de que os problemas de saúde interferem na vida escolar e carecem de uma atenção especial. Além disso, as lacunas evidenciadas poderão indicar caminhos para ajustes nas etapas futuras do programa.

\section{REFERÊNCIAS}

BRASIL. Ministério da Saúde. As cartas da promoção da Saúde. Brasília, DF: Ministério da Saúde, 2002. Disponível em: https://bvsms.saude.gov.br/bvs/publicacoes/cartas_promocao.pdf. Acesso em: 23 out. 2020.

BRASIL. Ministério da Saúde. Portaria $n^{\circ}$ 687, de 30 de março de 2006. Aprova a Política de Promoção da Saúde. Brasília, DF: Ministério da Saúde, 2006. Disponível em: http://189.28.128.100/dab/docs/legislacao/portaria687_30_03_06.pdf. Acesso em: 27 out. 2020.

BRASIL. Decreto ํo. 6.286, de 5 de dezembro de 2007. Institui o Programa Saúde na Escola - PSE, e dá outras providências. Diário Oficial da União: seção 1, Brasília, DF, p. 2, 6 dez. 2007. Disponível em: 
https://www2.camara.leg.br/legin/fed/decret/2007/decreto-6286-5-dezembro-2007-565691-publicacaooriginal-89439pe.html. Acesso em: 27 out. 2020.

BUSS, Paulo Marchiori; CARVALHO, Antônio Ivo de. Desenvolvimento da promoção da saúde no Brasil nos últimos vinte anos (1988-2008). Ciência \& Saúde Coletiva, Rio de Janeiro, v. 14, n. 6, p. 2305-2316, 2009.

DONDONI, Daniele. Programa saúde na escola: a intersetorialidade saúde e educação. 2016. 123 f. Dissertação (Mestrado em Educação) - Universidade Estadual do Oeste do Paraná, Cascavel, 2016.

FIGUEIREDO, Túlio Alberto Martins de; MACHADO, Vera Lúcia Taqueti; ABREU, Margaret Mirian Scherrer de. A saúde na escola: um breve resgate histórico. Ciência \& Saúde Coletiva, Rio de Janeiro, v. 15, n. 2, p. 397-402, 2010. Disponível em: https://www.scielo.br/j/csc/a/XK3j9btfm6xTzQsRYCBgWgr/abstract/?lang=pt. Acesso em: 20 out. 2020.

GARAJAU, Narjara I. Articulação intersetorial: uma estratégia de gestão para o Programa Cozinha Comunitária. 2013. Dissertação (Mestrado em Gestão Social, Educação e Desenvolvimento Local) - Centro Universitário UMA, Belo Horizonte, 2013a.

GARAJAU, Narjara I. Reflexões sobre a intersetorialidade como estratégia de gestão social. In: SIMPÓSIO MINEIRO DE ASSISTENTES SOCIAIS, 3., 2013, Belo Horizonte. Anais [...]. Belo Horizonte: CRESS, 2013b. p. 1-12.

JUNQUEIRA, Luciano A. Prates. A gestão intersetorial das políticas sociais e o terceiro setor. Saúde e Sociedade, São Paulo, v. 13, n. 1, p. 25-36, jan./abr. 2004. Disponível em: https://www.scielosp.org/article/sausoc/2004.v13n1/25-36/pt/. Acesso em: 6 out. 2020 .

JUNQUEIRA, Luciano A. Prates. Descentralização e intersetorialidade: a construção de um modelo de gestão municipal. Revista de Administração Pública, Rio de Janeiro, v. 32, n. 2, mar./abr. 1998. Disponível em: https://www.scielosp.org/article/sausoc/2004.v13n1/25-36/pt/. Acesso em: 15 out. 2020.

JUNQUEIRA, Luciano A. Prates; INOJOSA, Rose Marie; KOMATSU, Suely. Descentralização e intersetorialidade na gestão pública municipal do Brasil: a experiência de Fortaleza. In: CONCURSO DE ENSAYOS DEL CLAD, 11., 1997, Caracas. Anais [...]. Caracas: CLAD, 1997. p. 63-124.

LÜDKE, Menga; ANDRÉ, Marli E. D. A. Pesquisa em educação: abordagens qualitativas. São Paulo: EPU, 2013.

MORAES, Roque. Uma tempestade de luz: a compreensão possibilitada pela análise textual discursiva. Ciência \& Educação, Bauru, v. 9, n. 2, p. 191-210, 2003. Disponível em: https://www.scielo.br/j/ciedu/a/SJKF5m97DHykhL5pM5tXzdj/?lang=pt. Acesso em: 30 out. 2020.

MORAES, Roque; GALIAZZI, Maria do Carmo. Análise textual discursiva. Ijuí: Editora Unijuí, 2007.

OPAS. Organização Pan-Americana da Saúde. Escolas promotoras da saúde: experiências no Brasil. Brasília, DF: OPAS Brasil, 2006. Disponível em: https://bvsms.saude.gov.br/bvs/publicacoes/escolas_promotoras_saude_experiencias_brasil_p1.pdf. Acesso em: 12 out. 2020.

RICHARDSON, Roberto Jarry. Pesquisa social: métodos e técnicas. São Paulo: Atlas, 2014.

SANTOS, Natalia N. A intersetorialidade como modelo de gestão das políticas de combate à pobreza no Brasil: o caso do Programa Bolsa Família no Município de Guarulhos. 2011. Dissertação (Mestrado Acadêmico em Administração Pública e Governo) Escola de Administração de Empresas, Fundação Getúlio Vargas, São Paulo, 2011.

WIMMER, Gerd Ferreira; FIGUEIREDO, Gustavo de Oliveira. Ação coletiva para qualidade de vida: autonomia, transdisciplinaridade e intersetorialidade. Ciência \& Saúde Coletiva, Rio de Janeiro, v. 11, n. 1, p. 145-154, 2006. Disponível em: https://www.scielo.br/j/csc/a/3WJrhwNPmxrkyLtXRzLqGxk/?format=pdf\&lang=pt. Acesso em: 23 out. 2020.

\section{$(\mathrm{cc})$ EY}

Este trabalho está licenciado com uma Licença Creative Commons - Atribuição 4.0 Internacional. 